\title{
Some provisions of calculations of hydraulic structures according to Russian norms and American standards
}

\author{
Dmitry Kozlov ${ }^{*}$ \\ Moscow State University of Civil Engineering, Yaroslavskoe shosse, 26, Moscow, 129337, Russia
}

\begin{abstract}
Ensuring the safety of hydraulic structures should be carried out, including calculations of the stress-strain state of the system "structure-base" by the method of limit States. A summary system of reliability coefficients, a combination of loads and operating conditions for different design cases is presented. Considered the stability condition of the concrete dam on the shift on the substrate. A comparison of the values of the generalized dam stability coefficients (reserve) according to Russian norms and American standards is performed. It is shown that when comparing the numerical values of the strength and stability coefficients regulated in the Russian norms and American standards, it is necessary to take into account the methods of determining the strength characteristics of materials, the practice of taking into account loads and effects, as well as the methods of computational studies of the stress-strain state of structures and their bases.
\end{abstract}

\section{Introduction}

A variety of hydraulic structures for functional purposes and industry affiliation creates some difficulties in solving the problems of their own safety. Given the importance of hydraulic structures for various sectors of the economy, which are part of power plants, water transport systems, water supply systems and irrigation, special attention should be paid to own the security of such facilities, most of which were built 50-60 years ago.

Ensuring the safety of hydraulic structures should be carried out, including calculations of hydraulic, filtration and temperature regimes, as well as the stress-strain state of the system "structure - base", based on the results of calculations by the method of limit States.

\section{Methods}

For the limit state is taken such that the hydraulic structure (design) or its base ceases to meet the specified operational requirements. This means that:

\footnotetext{
* Corresponding author: kozlovdv@mgsu.ru
} 
- the magnitude of the forces and stresses developing in the structure (structure) or the base shall not exceed the carrying capacity of the structure (limit States of the first group - for unsuitability for operation);

- the value of deformations (displacements) of the structure shall not exceed the permissible for the normal operation of the structure (limit States of the second group - for unsuitability for normal operation).

The requirements of strength calculation are reduced to ensure that the values of forces, stresses, strains and displacements arising in the structure from the loads do not exceed the limits determined in accordance with the design standards.

The first limit state of the structure (strength or stability) occurs when the calculated generalized load $\mathrm{f}$ reaches the calculated value of the generalized carrying capacity of the structure (base). The calculations of the first group of limit States include the calculations of the total strength and stability of the system "structure-base"; the filtration strength of the base and the structure, on which the strength of the structure as a whole depends.

The second limit state assumes calculations of local, including filtration, strength of the base and structure; cracks and construction seams opening; strength of structural elements of the structure.

\section{Results}

In the calculations of hydraulic constructions, structures and grounds to comply with a condition to ensure that occurrence of the limit state, i.e. the assessment of onset of first limiting condition produced by the condition:

In formula (1):

$$
\gamma_{n} \gamma_{l c} F\left(\gamma_{f}\right) \leq \gamma_{c} R
$$

$\gamma_{n}$ - factor of reliability on responsibility (purpose) of the construction; $\gamma_{l c}$ - coefficient of combination of loads; $\gamma_{c}$ - coefficient of working conditions accepted according to $[1,2]$;

$F, R$ - respectively, the calculated values of the generalized force effect, taking into account the reliability factor for the load $\gamma_{f}$ and the generalized bearing capacity of the structure.

Load $F=F\left(\gamma_{f}\right)=\gamma_{f} F_{\text {norm }}$ is determined by multiplying the standard load value of $F_{\text {no rm }}$ by the corresponding load reliability factor $\gamma_{f}: F=F\left(\gamma_{f}\right)=\gamma_{f} F_{\text {norm }}$.

Normative values of loads $F_{\text {norm }}$ should be determined by the normative documents for the design of certain types of hydraulic structures, their structures and bases.

The value of the load reliability factor $\gamma_{f}$, when calculating the limit States of the first group should be taken in accordance with [2] and table 1.

Table 1. The coefficient of reliability for the load.

\begin{tabular}{|l|c|}
\hline \multicolumn{1}{|c|}{ Loads and impacts } & $\gamma_{f}$ \\
\hline $\begin{array}{l}\text { Water pressure directly on the surface of the structure and the base; power } \\
\text { effect of filtering water; wave pressure; pore pressure }\end{array}$ & 1,00 \\
\hline Own weight of the structure (without the weight of the soil) & $1,05(0,95)$ \\
\hline The weight of the soil (vertical pressure from weight of soil) & $1,10(0,90)$ \\
\hline The lateral pressure of soil & $1,20(0,80)$ \\
\hline Sediment pressure & 1,20 \\
\hline Ice load & 1,10 \\
\hline Loads from lifting and handling vehicles & 1,20 \\
\hline Seismic impact & 1,00 \\
\hline
\end{tabular}


The value of the coefficient of working conditions $\gamma_{c}$, taking into account the type of hydraulic structures and the base, features of the design and the approximation of the design schemes, for example, for concrete dams is taken according to [2] and table 2.

Table 2. The values of coefficient of operating conditions.

\begin{tabular}{|c|c|}
\hline $\begin{array}{c}\text { Types of calculations of dams and factors causing the introduction of } \\
\text { coefficients of working conditions }\end{array}$ & $\gamma_{c}$ \\
\hline $\begin{array}{l}\text { Calculations of stability of concrete (reinforced concrete) dams on semi- } \\
\text { basement and non-rock foundations }\end{array}$ & 1,00 \\
\hline $\begin{array}{l}\text { Calculations of stability of concrete dams (gravity and buttress) on rock } \\
\text { foundations for shear surfaces passing through: } \\
\text { (a) cracks in the base mass } \\
\text { (b) the contact concrete-rock and in the mountains the Foundation of the } \\
\text { partly cracked, partly for the monolith }\end{array}$ & $\begin{array}{l}1,00 \\
0,95\end{array}$ \\
\hline Calculations of the stability of the coast the abutments arch & 0,75 \\
\hline
\end{tabular}

The value of the reliability coefficient for the responsibility (class) of the structure $\gamma \mathrm{n}$, taking into account the degree of responsibility, the capital of the structure and the significance of the possible consequences in the event of a limit state (accident, flooding), is taken into account when calculating the limit States according to [2] and table 3.

Table 3. The value of the reliability coefficient on the responsibility (class) structures.

\begin{tabular}{|c|c|c|c|c|}
\hline \multicolumn{4}{|c|}{ Limit States of group 1} & \multirow{3}{*}{$\begin{array}{l}\text { Limit state of 2-nd } \\
\text { group }\end{array}$} \\
\hline \multicolumn{4}{|c|}{ Construction class } & \\
\hline I & II & III & IV & \\
\hline 1,25 & 1.20 & 1,15 & 1,10 & 1,00 \\
\hline
\end{tabular}

The value of the load combination factor $\gamma_{l c}$ in the calculations for the first group of limit states is taken according to [2] and table 4, and in the calculations for the second group of limit states - equal to 1.00 .

Table 4. Load combination ratio values.

\begin{tabular}{|c|c|c|c|c|}
\hline \multicolumn{5}{|c|}{ Load combination } \\
\hline \multicolumn{2}{|c|}{ The main combination (Usual) } & \multicolumn{2}{|c|}{ Special combination (Unusual) } \\
\hline the period of \\
normal operation & $\begin{array}{c}\text { the period of } \\
\text { construction and } \\
\text { repair }\end{array}$ & $\begin{array}{c}\text { including seismic } \\
\text { at the level of the } \\
\text { project earthquake } \\
\text { (OBE) annual } \\
\text { probability of } 0.01 \\
\text { and less }\end{array}$ & $\begin{array}{c}\text { when a special } \\
\text { load, in addition to } \\
\text { seismic annual } \\
\text { probability of } \\
0.001 \text { and less }\end{array}$ & $\begin{array}{c}\text { at seismic } \\
\text { load of the } \\
\text { maximum } \\
\text { calculated } \\
\text { earthquake } \\
\text { level MCE }\end{array}$ \\
\hline 1,00 & 0,95 & 0,95 & 0,90 & 0,85 \\
\hline
\end{tabular}

In foreign practice, the design earthquake is indicated by OBE (Operating basic earthquake) and the maximum credible earthquake - MCE (Maximum credible earthquake).

The main combination of loads and impacts during normal operation usually includes short-term loads with an annual probability of more than 0.01 . And seismic impacts should be carried out by [3].

Thus for dams of I and II classes calculation is carried out on two levels of seismic influences: OBE and MCE, and for dams of III and IV classes - only on OBE. 
A summary system of all the above coefficients for different calculated cases is given in table 5 .

Table 5. Values of reliability factors, combination of loads and working conditions.

\begin{tabular}{|c|c|c|c|c|c|c|c|c|}
\hline \multirow{4}{*}{$\begin{array}{l}\text { Estimated } \\
\text { cases }\end{array}$} & \multicolumn{8}{|c|}{ Limiting state } \\
\hline & \multicolumn{6}{|c|}{1 group } & \multicolumn{2}{|c|}{ 2-nd group } \\
\hline & \multicolumn{4}{|c|}{$\gamma_{n}$} & \multirow{2}{*}{$\gamma_{l c}$} & \multirow{2}{*}{$\gamma_{c}$} & \multirow{2}{*}{$\gamma_{n}$} & \multirow{2}{*}{$\gamma_{l c}$} \\
\hline & $\mathrm{I}$ & II & III & IV & & & & \\
\hline Building-repair & \multirow{3}{*}{1,25} & \multirow{3}{*}{1,20} & \multirow{3}{*}{1,15} & \multirow{3}{*}{1,10} & 0,95 & \multirow{3}{*}{$\begin{array}{r}1,00 \\
(0,95)\end{array}$} & \multirow{3}{*}{1,00} & \multirow{3}{*}{1,00} \\
\hline Usual & & & & & 1,00 & & & \\
\hline Unusual & & & & & $0,85 \ldots 0,95$ & & & \\
\hline
\end{tabular}

Under the influence of external forces, a hydraulic structure, for example, a dam, must be stationary (not to move and not to tip over), to be stable. Performing stability calculations, evaluate the ratio of holding and shear forces. It is required that the dam has some margin of stability, measured by the factor of stability.

The horizontal forces acting on the dam: the horizontal component of water pressure on the upstream and downstream faces of the dam; the pressure of sediments from the upper tail; the pressure of the ice and waves. Vertical forces acting on the dam: own weight of the dam body; vertical component of water pressure; weighing and filtration pressure on the bottom of the dam.

All the forces acting on the hydraulic structure, after the summation, can be represented by two components: horizontal $T$ and vertical $G$. The two main types of equilibrium: the structure will be shifted by the force $T$ on the base, or the structure will be tilted by the force $T$ and the counter-pressure force $W$ around the lower edge of the dam.

Next, we consider only the stability of the concrete dam to shift on the surface of the base. Calculation of stability of gravitational dams on shift is carried out according to [4]. The resistance of the structure to the shear force $T$ is created by the force proportional to the vertical component $G$ and equal to $f^{*} G$ (excluding the coupling force), where $f$ is the shear resistance parameter equal to $0.2 \ldots 0.8$, depending on the properties of the base and the dam material. The structure will be stable against shear if $T \leq f^{*} G$.

Calculation of stability of the dam on shift is carried out by calculation of factor of a stock of $K_{\mathrm{Z}}=(G \operatorname{tg} \varphi+C b) / T$, where $b$ is the width of the sole of the dam, comparing it then with admissible factor of a stock. The calculated values of the safety factor should not be less than acceptable, but also a significant excess of them is undesirable.

Thus, the criteria of reliability (strength and stability) and their numerical values for hydraulic structures in Russia are regulated by national standards, codes of practice and other normative documents approved at the state level.

The most common in the world practice of designing hydraulic structures received the standards of American organizations:

- US Army Corps of Engineers - 1995 (USACE). Provides civil and military services in the U.S. and abroad, including dams, canals, and flood protection. The mission of the USACE planning, design, construction and operation of waterworks and dams, the implementation of other projects in the field of civil construction, including control of the maximum runoff and flood protection, dredging for navigation, environmental regulation and ecosystem restoration.

- US Bureau of Reclamation (USBR). Controls the management of water resources. Coordinates irrigation and dam construction at the national level. The official mission of reclamation is "to manage, develop and protect water and related resources in an environmentally and economically sound manner in the interests of American society". 
- Federal Energy Regulatory Commission (FERC). Regulates the transmission and wholesale of electricity and natural gas in the system of trade between the States.

Let's write down the condition (1), which is true for both Russian and American standards:

$$
F\left(\gamma_{f}\right) \leq \gamma_{c} R /\left(\gamma_{n} \gamma_{l c}\right) \text { or } F\left(\gamma_{f}\right) \leq R / \gamma_{\mathrm{st}}
$$

where: $\gamma_{\mathrm{st}}$ - generalized construction stability factor (the value showing the ability of the structure to withstand the load applied to it above the design), $\gamma_{\mathrm{st}}=\left(\gamma_{n} \gamma_{l c}\right) / \gamma_{c}$.

In calculations of stability of concrete dams (gravitational and buttress) as constructions of the I class on the rock bases for the surfaces of the shift passing on cracks in the massif of the basis or contact concrete-rock and in the massif of the basis partially on cracks, partially on the monolith, numerical values of the generalized coefficient of stability of the dam $\gamma_{\mathrm{st}}$ for various settlement cases of combination of loadings and influences on the first group of limit states can be accepted as in table 6 .

Table 6. Values of the generalized stability coefficient $\gamma_{\mathrm{st}}$ Russian standards (for dams of I class).

\begin{tabular}{|c|c|c|c|}
\hline \multirow{3}{*}{\multicolumn{2}{|c|}{$\begin{array}{l}\text { The combination of pressures and impacts } \\
\text { (design cases) }\end{array}$}} & \multirow{2}{*}{\multicolumn{2}{|c|}{$\gamma_{\text {st }}$}} \\
\hline & & & \\
\hline & & massif of the base & $\begin{array}{c}\text { and in the array of the } \\
\text { base }\end{array}$ \\
\hline \multicolumn{2}{|l|}{ Usual } & 1,25 & 1,32 \\
\hline \multicolumn{2}{|c|}{ Unusual (Special) without seismic effects } & 1,13 & 1,18 \\
\hline \multirow{2}{*}{$\begin{array}{l}\text { Unusual (Special) with } \\
\text { seismic effects }\end{array}$} & OBE & 1,19 & 1,25 \\
\hline & MCE & 1,06 & 1,12 \\
\hline \multicolumn{2}{|l|}{ Building-repair } & 1,19 & 1,25 \\
\hline
\end{tabular}

Comparison of the values of the generalized stability factors of $\gamma_{\mathrm{st}}$ according to Russian norms and American standards [5,6] is given in table 7.

Table 7. A comparison of the values of generalized coefficient of stability of the dam.

\begin{tabular}{|c|c|c|c|c|c|c|c|c|}
\hline \multicolumn{2}{|c|}{$\begin{array}{l}\text { The combination of } \\
\text { pressures and impacts }\end{array}$} & \multicolumn{7}{|c|}{ Stability factor } \\
\hline \multirow{3}{*}{$\begin{array}{c}\text { USACE - } \\
1995, \\
\text { USBR, } \\
\text { FERC- } 2002 \\
\text { Load } \\
\text { Condition }\end{array}$} & \multirow{3}{*}{$\begin{array}{l}\text { Russian } \\
\text { codes of } \\
\text { practice }\end{array}$} & $\begin{array}{l}\text { USACE - } \\
1995\end{array}$ & \multicolumn{2}{|c|}{ USBR } & \multicolumn{2}{|c|}{ FERC - 2002} & \multicolumn{2}{|c|}{$\begin{array}{l}\text { Russian codes of } \\
\text { practice }\end{array}$} \\
\hline & & \multirow{2}{*}{$\begin{array}{l}\text { Minimum } \\
\text { Sliding } \\
\text { factor of } \\
\text { safety FS }\end{array}$} & \multicolumn{2}{|c|}{ Shift by } & \multicolumn{2}{|c|}{$\begin{array}{l}\text { When using shear } \\
\text { strength }\end{array}$} & \multicolumn{2}{|c|}{ Shift by } \\
\hline & & & $\begin{array}{l}\text { crack } \\
\text { shear }\end{array}$ & $\begin{array}{l}\text { con- } \\
\text { tact }\end{array}$ & $\begin{array}{l}\text { peak } \\
\text { strength }\end{array}$ & residual & $\begin{array}{l}\text { crack } \\
\text { shear }\end{array}$ & $\begin{array}{l}\text { the contact } \\
\text { concrete- } \\
\text { rock }\end{array}$ \\
\hline Usual & Usual & 2,00 & 4,00 & 3,00 & 3,00 & 1,50 & 1,56 & 1,65 \\
\hline \multirow{3}{*}{ Unusual } & $\begin{array}{l}\text { without } \\
\text { seismic }\end{array}$ & \multirow{3}{*}{1,70} & \multirow{3}{*}{2,70} & \multirow{3}{*}{2,00} & \multirow{3}{*}{2,00} & \multirow{3}{*}{1,30} & 1,41 & 1,48 \\
\hline & OBE & & & & & & 1,49 & 1,56 \\
\hline & $\begin{array}{l}\text { Building- } \\
\text { repair }\end{array}$ & & & & & & 1,49 & 1,56 \\
\hline \multirow[b]{3}{*}{ Extreme } & with PMF & \multirow[b]{3}{*}{1,30} & \multirow[b]{3}{*}{1,30} & \multirow[b]{3}{*}{1,00} & \multirow[b]{3}{*}{1,30} & \multirow[b]{3}{*}{1,00} & 1,41 & 1,48 \\
\hline & MCE & & & & & & 1,33 & 1,40 \\
\hline & $\begin{array}{l}\text { Building- } \\
\text { repair with } \\
\text { OBE }\end{array}$ & & & & & & - & - \\
\hline Post-seismic & - & 1,30 & - & - & 2,00 & 1,10 & - & - \\
\hline
\end{tabular}


PMF (probable maximum flood) - maximum probable flood. Values of shear stability coefficients for normative values of shear resistance parameters.

\section{Discussion}

A significant difference in the values of the generalized stability coefficients according to Russian norms and American standards with the main combination of loads is explained by the fact that the normative documents of American organizations use the peak shear strength, while the Russian norms regulate the use of residual strength (due to differences in the procedure for determining the shear resistance parameters).

In addition, in American standards there is a calculated post-seismic case (post-seismic), which is absent in Russian regulations. The stability calculations for this calculation case use the residual values of the tangent of the internal friction angle $\operatorname{tg} \varphi$ and the coupling $C$ in the Coulomb-Mohr failure criteria.

When comparing the numerical values of the strength and stability coefficients, regulated in the Russian norms and American standards, at first glance shows a more bold and risky approach to the justification of the reliability of facilities in Russia. But it is necessary to take into account the methods of determining the strength characteristics of materials, the practice of accounting for loads and impacts, as well as take into account the methods of computational studies of the stress-strain state of structures (structures) and their bases.

This work was financially supported by Ministry of Science and Higher Education of the Russian Federation (\#NSh-3492.2018.8).

\section{References}

1. Concrete and reinforced concrete dams. SP 40.13330.2012 «SNiP 2.06.06-85» (2012) https://yandex.ru/search/text=concrete

2. Hydraulic Structures. Basic statements. SP 58.13330.2012 «SNiP 33-01-2003» (2012) https://yandex.ru/search/text=Hydraulic

3. Seismic Building Design Code. SP 14.13330.2014 «SNiP II-7-81*» (2014) https://yandex.ru/search/text=Seismic

4. Foundation of hydraulic structures. SP 23.13330.2011 «SNiP 2.02.02-85» (2011) https://yandex.ru/search/text=Foundation

5. US Army Corps of Engineers (USACE).EM-1110-2-2220.Gravity Dam Design (1995) https://yandex.ru/search/text=US

6. US Army Corps of Engineers (USACE). EM-1110-2-2006. Engineering and Design Roller Compacted Concreted (2000) https://yandex.ru/search/text=US 